\title{
Stereotactic robotic body radiotherapy for patients with oligorecurrent pulmonary metastases
}

Patrick Berkovic ${ }^{1,2^{*}} \mathbb{D}$, Akos Gulyban²,3, Gilles Defraene ${ }^{1}$, Laurie Swenen², David Dechambre ${ }^{2}$, Paul Viet Nguyen², Nicolas Jansen², Carole Mievis ${ }^{2}$, Pierre Lovinfosse ${ }^{2}$, Levente Janvary ${ }^{2}$, Maarten Lambrecht ${ }^{1}$ and Gert De Meerleer ${ }^{1}$

\begin{abstract}
Background: Our aim is to report treatment efficacy and toxicity of patients treated by robotic (Cyberknife $\left.{ }^{\circledast}\right)$ stereotactic body radiotherapy (SBRT) for oligorecurrent lung metastases (ORLM). Additionally we wanted to evaluate influence of tumor, patient and treatment related parameters on local control (LC), lung and distant progression free- (lung PFS/Di-PFS) and overall survival (OS).
\end{abstract}

Methods: Consecutive patients with up to 5 ORLM (confirmed by FDG PET/CT) were included in this study. Intended dose was 60Gy in 3 fractions (prescribed to the $80 \%$ isodose volume). Patients were followed at regular intervals and tumor control and toxicity was prospectively scored. Tumor, patient and treatment data were analysed using competing risk- and Cox regression.

Results: Between May 2010 and March 2016, 104 patients with 132 lesions were irradiated from primary lung carcinoma (47\%), gastro-intestinal (34\%) and mixed primary histologies (19\%). The mean tumor volume was $7.9 \mathrm{cc}$. After a median follow up of 22 months, the 1, 2 and 3 year LC rate (per lesion) was $89.3,80.0$ and $77.8 \%$ respectively. The corresponding (per patient) 1,2 and 3 years lung PFS were 66.3, 50.0, 42.6\%, Di-PFS were 80.5, 64.4, $60.6 \%$ and OS rates were $92.2,80.9$ and $72.0 \%$ respectively. On univariable analysis, gastro-intestinal (GI) as primary tumor site showed a significant superior local control versus the other primary tumor sites. For OS, significant variables were primary histology and primary tumor site with a superior OS for patients with metastases of primary Gl origin. LC was significantly affected by the tumor volume, physical and biologically effective dose coverage. Significant variables in multivariable analysis were BED prescription dose for LC and GI as primary site for OS. The vast majority of patients developed no toxicity or grade 1 acute and late toxicity. Acute and late grade 3 radiation pneumonitis (RP) was observed in 1 and 2 patients respectively. One patient with a centrally located lesion developed grade 4 RP and died due to possible RT-induced pulmonary hemorrhage.

Conclusions: SBRT is a highly effective local therapy for oligorecurrent lung metastases and could achieve long term survival in patients with favourable prognostic features.

Keywords: Lung-Oligometastases-Oligorecurrence-Cyberknife-prognostic factors-outcome

\footnotetext{
* Correspondence: patrick.berkovic@uzleuven.be

'Department of Radiation Oncology, University Hospitals Leuven, Herestraat 49, 3000 Leuven, Belgium

${ }^{2}$ Department of Radiation Oncology, University Hospital of Liège, Avenue de L'Hòpital 1, 4000 Liège, Belgium

Full list of author information is available at the end of the article
}

(c) The Author(s). 2020 Open Access This article is licensed under a Creative Commons Attribution 4.0 International License, which permits use, sharing, adaptation, distribution and reproduction in any medium or format, as long as you give appropriate credit to the original author(s) and the source, provide a link to the Creative Commons licence, and indicate if changes were made. The images or other third party material in this article are included in the article's Creative Commons licence, unless indicated otherwise in a credit line to the material. If material is not included in the article's Creative Commons licence and your intended use is not permitted by statutory regulation or exceeds the permitted use, you will need to obtain permission directly from the copyright holder. To view a copy of this licence, visit http://creativecommons.org/licenses/by/4.0/. The Creative Commons Public Domain Dedication waiver (http://creativecommons.org/publicdomain/zero/1.0/) applies to the data made available in this article, unless otherwise stated in a credit line to the data. 


\section{Background}

Pulmonary tissue is a frequent site of metastatic seeding, with epithelial malignancies and sarcoma having a high tendency to develop lung metastases [1, 2]. Resection of lung metastases (metastasectomy) has become a widespread and accepted standard therapy [2, 3]. However, evidence for pulmonary metastasectomy is weak as no randomized clinical trials exist to support its benefit. In case of oligometastatic lung disease (OMLD) [4], less invasive interventions such as radiofrequency- and microwave ablation and stereotactic body radiotherapy (SBRT) have been described as a valid alternative to surgery [5].

SBRT for OMLD yields high local control and low toxicity rates; in case of limited (maximal 5) lung metastases, the 2-year local control varies between 78 and 96\% [6-10]. The term OMLD has been further refined with the concept of oligorecurrent lung metastases (ORLM), defined as the development of metachronous lung oligometastases after radical treatment of the primary tumor [11]. This refinement rules out patients presenting with OMLD at initial diagnosis or OMLD with an uncontrolled primary tumor. Several studies suggest an improved outcome for patients with ORLM when compared to synchronous OMLD [12, 13].

The major challenge when delivering SBRT to lung metastases is to manage respiratory motion of both tumor and normal tissues. Breathing control strategies such as breath-hold, gating, tumor tracking and motion management techniques have been implemented to deal with this challenge $[14,15]$. One of those strategies is the Cyberknife ${ }^{\ominus}$ synchrony (Accuray Inc., Sunnyvale, CA), which performs real-time tumor tracking. This allows for a high level of precision while treating the patient in the comfort of free breathing [16].

The primary aim of this retrospective study is to report on local control, lung and distant progression free survival and overall survival of patients with ORLM treated with SBRT using the Cyberknife ${ }^{\circledast}$. The secondary aim is to report on SBRT-induced acute and late toxicity and to identify prognostic factors influencing the treatment outcome.

\section{Methods}

\section{Patient, tumor and treatment characteristics}

Consecutive patients with up to 5 ORLM were included in this study for Cyberknife treatment at the Liege University Hospital, Belgium. All patients were referred for SBRT after full staging including baseline registration of the pulmonary function, chest and abdominal diagnostic computed tomography (CT) and [18F]-fluorodeoxyglucose (FDG) positron emission tomography (PET)-CT imaging confirming local control at the primary tumor site and the absence of non-pulmonary metastases. Indications for SBRT were discussed and approved by the multi-disciplinary tumor board. Patients were informed of the intent, possible side effects and practical modalities and provided consent for treatment prior to SBRT. Since the study was retrospective, informed consent was waived. We included patients with both de-novo metachronous (57 lesions)-and repeat ORLM (75 lesions) according to the definition proposed by Guckenberger et al. [17]. Lesions in any location within the lung were included in this analysis, irrespective of prior treatments including systemic therapy, surgery or previous radiotherapy for their primary lesion or prior metastases (Table 1). Exclusion criteria were heavily compromised pulmonary function tests with grade IV COPD, co-existing ILD and IPF, pleural effusion, metastases with diameter $>6 \mathrm{~cm}$ and patients with a life expectancy of less than 6 months.

\section{Cyberknife planning and treatment}

A majority of patients had radio-opaque $3 \mathrm{~mm}$ long gold fiducials (Goldlock, Beampoint, Kista, Sweden) inserted alongside the tumor by CT-guided transthoracic punction by a dedicated interventional radiologist and placed according to Accuray's guidelines [18]. Treatment preparation, planning characteristics and tracking options of the Cyberknife system have been previously described $[19,20]$. In short, real time tracking was preferred either on implanted fiducials (Synchrony ${ }^{\odot}$ ) or - in case of contra-indications and clear identification of tumor projection on both orthogonal detector panels -using image guidance (Xsight Lung ${ }^{\oplus}$ ), leaving the vertebra based position verification (XsightSpine ${ }^{\oplus}$ ) as last option. Left and right lung, oesophagus, heart, thoracic wall or ribs, trachea, spinal canal, great vessels, ipsilateral brachial plexus (for sulcus superior lesions) and a $4 \mathrm{~mm}$ thick skin area were delineated as organs at risk. The expiration CT scan was used as reference for treatment planning purpose. The gross tumor volume (GTV) was defined on this scan using mutual information from additional image modalities, and was expanded with $3 \mathrm{~mm}$ margin to create a CTV followed by manual modification in presence of adjacent anatomical borders. The planning target volume (PTV) was created by adding a 2 $\mathrm{mm}$ uniform margin around the CTV. Intended prescription was $60 \mathrm{~Gy}$ in $20 \mathrm{~Gy}$ per fraction for the $80 \%$ isodose, with at least $95 \%$ PTV coverage. The organs at risk (OAR) dose constraints reported by Timmerman [21] were always respected, using a risk-adapted fractionation scheme concept when necessary. The estimated fraction duration was kept below $70 \mathrm{~min}$ and the treatment sessions were delivered at an interval of 
Table 1 Patient and tumor characteristics

\begin{tabular}{|c|c|c|}
\hline & Per patients (1st lesion) & Per lesion/treatment \\
\hline \multicolumn{3}{|l|}{ Gender } \\
\hline Female & $49(47.1 \%)$ & $61(46.2 \%)$ \\
\hline Male & $55(52.9 \%)$ & $71(53.8 \%)$ \\
\hline \multicolumn{3}{|c|}{ Age (at SBRT, years) } \\
\hline Median (range) & $66.4(28.2-87.6)$ & $65.2(28.2-86.6)$ \\
\hline \multicolumn{3}{|c|}{ Location of the lesion } \\
\hline Periferal & & $80(61 \%)$ \\
\hline Central & & $52(39 \%)$ \\
\hline \multicolumn{3}{|l|}{ Primary sites } \\
\hline Lung & $49(47.1 \%)$ & \\
\hline Gastro-intestinal & $35(33.7 \%)$ & \\
\hline Other & $20(19.2 \%)$ & \\
\hline \multicolumn{3}{|l|}{ Primary histology } \\
\hline Adenocarcinoma & $67(64.4 \%)$ & $86(65.2 \%)$ \\
\hline Other & 37 (35.6\%) & $46(34.8 \%)$ \\
\hline \multicolumn{3}{|c|}{ Lesion treated at same time (on same $\mathrm{CT}$ ) } \\
\hline 1 & $82(78.8 \%)$ & \\
\hline 2 & $16(15.4 \%)$ & \\
\hline 3 & $4(3.8 \%)$ & \\
\hline 4 & $2(1.9 \%)$ & \\
\hline \multicolumn{3}{|c|}{ Prior chemotherapy for primary tumor } \\
\hline Yes & $25(24 \%)$ & $27(20.5 \%)$ \\
\hline No & $79(76 \%)$ & $105(79.5 \%)$ \\
\hline \multicolumn{3}{|l|}{ Performance status } \\
\hline 0 & $24(23.1 \%)$ & $29(22 \%)$ \\
\hline 1 & $71(68.3 \%)$ & 91 (68.9\%) \\
\hline 2 & $9(8.7 \%)$ & $12(9.1 \%)$ \\
\hline \multicolumn{3}{|c|}{ Previous treatments (per patient) ${ }^{a}$} \\
\hline Surgery & $45(34.1 \%)$ & \\
\hline Chemotherapy & 47 (35.6\%) & \\
\hline Radiotherapy & $42(31.8 \%)$ & \\
\hline Other & 57 (43.2\%) & \\
\hline
\end{tabular}

${ }^{a}$ combined treatments are counted separately

minimum $40 \mathrm{~h}$. Details on the dose calculation algorithms (Ray Tracing followed by recalculation with Monte Carlo) can be found in our previous work [20, 22].

\section{Follow up and toxicity evaluation}

Patients were evaluated for acute toxicity after the last fraction, at 2 weeks, and then in function of the referring team at an interval of 2 to 4 months. Treatment response was evaluated at this interval by serial contrast enhanced spiral CT and was defined according to the Response Evaluation Criteria in Solid Tumors version 1.1 [23]. In case of (serial) CT-features suggesting progression of the treated lesion, a FDG PET/CT was performed followed by a fine needle biopsy (if feasible) to confirm local failure.

Local control (LC) was defined as one of the following: complete response, partial response or stable disease (CR, PR or SD). Recurrences within the PTV were classified as local failure whereas recurrences in the same or other lobe, beyond the PTV were considered as metachronous pulmonary metastases. Extra-pulmonary recurrences were classified as distant metastases. Toxicity was evaluated using the Common Terminology Criteria for Adverse Events v4.0 [24]. Toxicities occurring less than or equal to 3 months following SBRT were considered as acute whereas toxicities arising after 3 months were considered as late.

\section{Data analysis}

LC was analysed in a competing risk regression analysis. Lung and distant progression free-survival (L-PFS, DiPFS) and overall survival (OS) curves were evaluated by the (competing risk and) Kaplan-Meier analysis method. Data for LC were determined for each lesion separately, while the L-PFS, Di-PFS and OS were determined per patient originated from the day of the first SBRT treatment. Univariable analysis was performed using Gray's test and the log rank test for competing risk and Kaplan-Meier analysis, respectively. Clinical parameters were analysed for all outcome parameters. For LC, additional investigation included treatment planning related parameters such as number of fractions, target volumes, physical and biological effective dose (BED10 considering $\alpha / \beta=10$ ) and coverages for GTV, CTV and PTV in a systematic manner. Finally, multivariable analyses started with a preselection of the parameters based on their univariable $p$ value $(p<0.10)$ and their correlation (Pearson's correlation $r<0.7)$. The Fine and Gray and the Cox regression methods were followed for competing risk and Kaplan-Meier analysis, respectively. For all tests a $p$-value $<0.05$ was considered as statistically significant using Python packages (pandas 0.21.0, scipy 0.18.0 and lifelines 1.9.4.0) and $\mathrm{R}$ software (v.3.4.4, R Foundation for Statistical Computing, Vienna, Austria).

\section{Results}

Between May 2010 and March 2016 a total of 104 patients with 132 lesions were irradiated in 106 treatments. Sixteen, four and two patients were treated for respectively two, three and four synchronous lesions. In case of a second de-novo metachronous-or repeat ORLM, a new SBRT session was the treatment of choice in 42 patients. Table 1 contains detailed information on patient and tumor characteristics. 
Table 2 Tumor and treatment related parameters

\begin{tabular}{lll}
\hline & $\begin{array}{l}\text { Per patients } \\
\text { (1st lesion) }\end{array}$ & $\begin{array}{l}\text { Per lesion } \\
\text { (treatment) }\end{array}$ \\
\hline Prescription & & \\
3×6.67Gy (BED10: 33.36 Gy) & $0(0 \%)$ & $2(1.5 \%)$ \\
5x7Gy (BED10: 59.5 Gy) & $1(1 \%)$ & $3(2.3 \%)$ \\
5x8Gy (BED10: 72 Gy) & $5(4.8 \%)$ & $5(3.8 \%)$ \\
5x9Gy (BED10: 85.5 Gy) & $5(4.8 \%)$ & $7(5.3 \%)$ \\
5x10Gy (BED10: $100 \mathrm{~Gy})$ & $13(12.5 \%)$ & $15(11.4 \%)$ \\
5x11Gy (BED10: 115.5 Gy) & $9(8.7 \%)$ & $11(8.3 \%)$ \\
5x12Gy (BED10: 132 Gy) & $10(9.6 \%)$ & $11(8.3 \%)$ \\
3x15Gy (BED10: 112.5 Gy) & $2(1.9 \%)$ & $4(3.0 \%)$ \\
3x17Gy (BED10: 137.7 Gy) & $3(2.9 \%)$ & $1(0.8 \%)$ \\
3x20Gy (BED10: 180 Gy) & $56(53.8 \%)$ & $73(55.3 \%)$ \\
Tracking & & \\
Synchrony & $44(42.3 \%)$ & $56(42.4 \%)$ \\
Xsight Lung & $13(12.5 \%)$ & $16(12.1 \%)$ \\
Xsight Spine & $47(45.2 \%)$ & $60(45.5 \%)$ \\
RECIST & & $76(57.6 \%)$ \\
Complete Remission & $63(60.6 \%)$ & $15(11.4 \%)$ \\
Partian Remission & $12(11.5 \%)$ & $5(3.8 \%)$ \\
Stable Disease & $4(3.8 \%)$ & $36(27.3 \%)$ \\
Progressive Disease & $25(24 \%)$ & \\
\hline
\end{tabular}

Treatment execution

\section{Nr. of beams}

Average (Range)

Total MU

Average (Range)

Volumes (Mean, (Range) in cm3)

GTV

CTV

PTV

Dosimetric parameters (Mean, $(95 \% \mathrm{Cl})$ in $\mathrm{Gy}$ )

$\begin{array}{ll}\text { GTV-D98 } & 58.3(30.0-70.2) \\ \text { GTV-D90 } & 60.7(33.3-71.6) \\ \text { GTV-Dmean } & 64.7(43.2-73.2) \\ \text { GTV-D2 } & 68.9(48.5-75.2) \\ \text { GTV-BED10Gy D98 } & 162.6(49.1-234.6) \\ \text { GTV-BED10Gy D95 } & 167.4(52.8-238.3) \\ \text { GTV-BED10Gy D90 } & 172.4(55.7-242.6) \\ \text { GTV-BED mean } & 189.8(80.8-251.8) \\ \text { GTV-BED10Gy D2 } & 208.8(95.5-264.0) \\ \text { CTV-D98 } & 55.6(27.5-66.4) \\ \text { CTV-D90 } & 59.0(35.0-68.4) \\ \text { CTV-Dmean } & 63.6(43.3-71.4)\end{array}$

Table 2 Tumor and treatment related parameters (Continued)

\begin{tabular}{|c|c|c|}
\hline & $\begin{array}{l}\text { Per patients } \\
\text { (1st lesion) }\end{array}$ & $\begin{array}{l}\text { Per lesion } \\
\text { (treatment) }\end{array}$ \\
\hline CTV-BED10Gy D98 & & $150.8(44.0-213.6)$ \\
\hline CTV-BED10Gy D95 & & $157.5(51.3-218.4)$ \\
\hline CTV-BED10Gy D90 & & $163.9(61.3-224.2)$ \\
\hline CTV-BED mean & & $184.4(81.0-241.4)$ \\
\hline PTV-D98 & & $52.5(23.7-61.8)$ \\
\hline PTV-D90 & & $56.3(32.1-64.5)$ \\
\hline PTV-Dmean & & $62.0(42.6-69.5)$ \\
\hline PTV-BED10Gy D98 & & $137.6(37.0-189.2)$ \\
\hline PTV-BED10Gy D95 & & 144.7 (42.4-197.4) \\
\hline PTV-BED10Gy D90 & & $151.7(55.0-203.4)$ \\
\hline PTV-BED mean & & $176.5(79.0-231)$ \\
\hline
\end{tabular}

\section{Treatment characteristics}

The mean GTV and PTV volumes were 7.9 cc $(90 \% \mathrm{CI}$, 0.4-36.1) and 25.3 cc (90\% CI, 3.9-74.7) respectively. All treatments were delivered $3 \mathrm{x} /$ week on every other day in three or five fractions for respectively 59 and $41 \%$ of the patients to an average PTV median dose (D50) of 62.4 Gy (90\% CI, 44.4-69.4). This corresponds to an average PTV $_{\text {BED10 }}$ of $177.6 \mathrm{~Gy}(90 \% \mathrm{CI}, 83.9-229.7)$. The mean GTV and PTV D98\% were 58.3 Gy (90\% CI, 36.2-70.1) and 52.5 Gy (90\% CI, 31.6-61.7) respectively. Each treatment was delivered by an average of 120 (35-230) beams during a median of $45 \mathrm{~min}$ (30-63 min) session. Further dosimetric parameters are presented in Table 2.

\section{Treatment efficacy}

37,821 (11902-89,666) After a median follow up of 22.0 months (range: 1.561.0), the number of patients (lesions) at risk were 83 (104), 43 (25) and 16 (17) at 1, 2 and 3-year respectively. LC rate (based on the RECIST criteria, Table 2) - following each lesion separately - was $89.3 \%$ at first, $80.0 \%$ at second and $77.8 \%$ at third year. The corresponding - per patient - lung PFS and the Di-PFS rates at 1, 2 and 3 years were 66.3, 50.0, 42.6 and 80.5, 64.4, 60.6\% respectively. Associated $\mathrm{OS}$ rates at 1,2 and 3 years were 92.2, 80.9 and $72.0 \%$ (Fig. 1). Associations of variables with the outcome parameters are summarized in Tables 3 and 4 . In univariable analysis for LC, all clinical variables were marginally significant while gastro-intestinal (GI) as primary tumor site showed a significant superior local control versus the other primary tumor sites $(p=0.029)$. For lung PFS, a primary histology of adenocarcinoma $(p=0.023)$ and a primary tumor site other than lung $(p=0.043)$ were significantly superior. Regarding distant PFS, only PS $(p=0.060)$ was marginally significant in univariable analysis (no multivariable analysis required). For OS, significant variables 


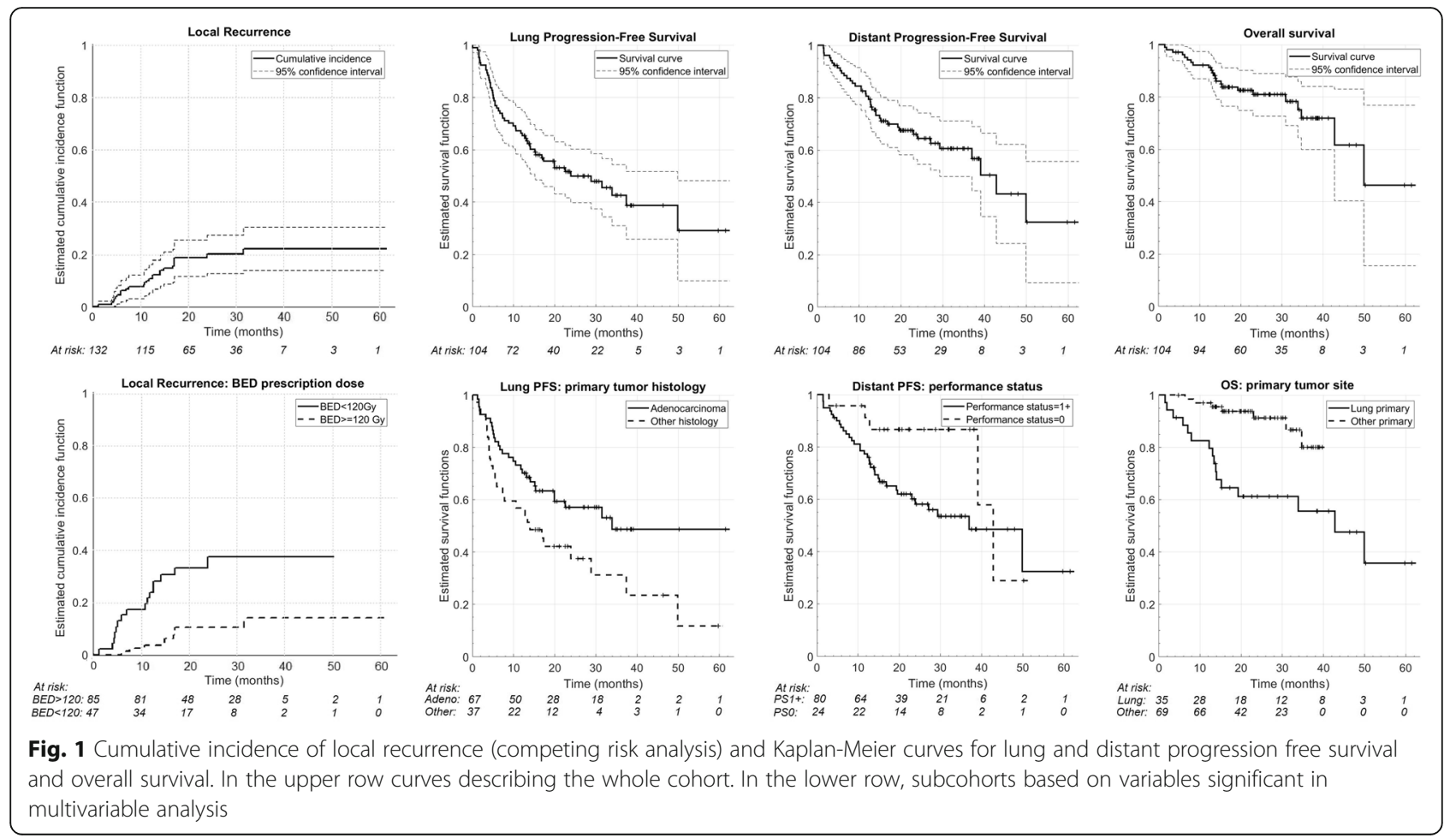

were primary histology $(p=0.009)$ and primary tumor site with a superior OS for patients with metastases of primary GI origin $(p=0.0015)$. GTV volumes correlated with local control $(p=0.0021)$. For GTV, CTV and PTV a physical dose coverage of 60Gy to at least $95 \%$ of the volume showed significant effect on the LC. A biologically effective dose coverage $(\alpha / \beta=10)$ of 160GyBED10 for both GTV and CTV to at least $95 \%$ of the volume was a statistically significant threshold for LC. GTV's near maximum physical (D2) and biologically effective (D2 $\left.2_{\mathrm{BED} 10}\right)$ doses of $65 \mathrm{~Gy}$ and $165 \mathrm{~Gy}_{\mathrm{BED} 10}$ respectively significantly impacted LC. Variables which remained significant in multivariable analysis (Table 5) were BED prescription dose (>120 Gy vs $<120 \mathrm{~Gy})$ for superior LC $(p=0.025)$ and GI as primary site for superior OS $(p=0.05)$.

\section{Toxicity}

The SBRT treatment was extremely well tolerated. Fiducial related events were low with $7 \%$ grade 1 and $2 \%$ grade 2 fiducial related pneumothorax without incidences of bleeding. The vast majority of patients developed no toxicity or grade 1 acute and late toxicity. Toxicity was not correlated with tumor location nor with the number of treated lesions. Only 1 patient developed acute grade 3 radiation pneumonitis (RP) and 2

Table 3 Univariable associations of outcome measures and clinical variables: Gray's test for LC, logrank test for lung PFS, distant PFS and OS

\begin{tabular}{|c|c|c|c|c|c|c|c|c|}
\hline \multirow{2}{*}{$\begin{array}{l}\text { Endpoint } \\
\text { Clinical variables }\end{array}$} & \multicolumn{2}{|l|}{ Local control } & \multicolumn{2}{|l|}{ Lung PFS } & \multicolumn{2}{|l|}{ Distant PFS } & \multicolumn{2}{|l|}{ Overall survival } \\
\hline & Hazard ratio $(95 \% \mathrm{Cl})$ & $p$ value & Hazard ratio $(95 \%$ Cl) & $p$ value & Hazard ratio $(95 \%$ Cl) & $p$ value & Hazard ratio $(95 \%$ Cl) & $p$ value \\
\hline $\begin{array}{l}\text { Primary histology } \\
\text { (adeno vs other) }\end{array}$ & $0.52(0.24-1.12)$ & 0.093 & $0.49(0.27-0.87)$ & 0.023 & $0.73(0.38-1.41)$ & 0.44 & $0.28(0.12-0.67)$ & 0.009 \\
\hline $\begin{array}{l}\text { Primary tumor site } \\
\text { (lung vs other) }\end{array}$ & $1.94(0.90-4.16)$ & 0.10 & $1.88(1.06-3.33)$ & 0.043 & $1.66(0.84-3.29)$ & 0.20 & $5.77(2.39-13.94)$ & $<0.001$ \\
\hline $\begin{array}{l}\text { Primary tumor site } \\
\text { (Gl vs other) }\end{array}$ & $0.36(0.15-0.90)$ & 0.029 & $0.66(0.39-1.14)$ & 0.17 & $0.86(0.45-1.64)$ & 0.77 & $0.24(0.10-0.54)$ & 0.0015 \\
\hline $\begin{array}{l}\text { Prior chemotherapy } \\
\text { (yes vs no) }\end{array}$ & $3.25(0.79-13.50)$ & 0.084 & $1.09(0.59-2.02)$ & 0.90 & $0.96(0.46-1.98)$ & 0.95 & $0.78(0.31-2.01)$ & 0.79 \\
\hline Age > 65 (yes vs no) & $0.49(0.21-1.14)$ & 0.090 & $0.94(0.55-1.60)$ & 0.92 & $0.65(0.34-1.24)$ & 0.25 & $0.95(0.42-2.16)$ & 0.93 \\
\hline $\begin{array}{l}\text { Performance status } \\
(1+\text { vs } 0)\end{array}$ & $3.63(0.88-14.90)$ & 0.056 & $0.76(0.40-1.46)$ & 0.52 & $2.10(1.04-4.25)$ & 0.060 & $2.58(1.01-6.58)$ & 0.082 \\
\hline Gender (male vs female) & $2.26(0.94-5.44)$ & 0.060 & $0.93(0.54-1.59)$ & 0.90 & $0.92(0.49-1.72)$ & 0.92 & $0.85(0.37-1.93)$ & 0.86 \\
\hline
\end{tabular}


Table 4 Univariable associations (Gray's test) of LC and dosimetric/treatment variables

\begin{tabular}{|c|c|c|}
\hline \multirow{2}{*}{$\begin{array}{l}\text { Endpoint } \\
\text { Dosimetric variables }\end{array}$} & \multicolumn{2}{|l|}{ Local control } \\
\hline & $\begin{array}{l}\text { Hazard ratio } \\
(95 \% \mathrm{Cl})\end{array}$ & $p$ value \\
\hline Number of fractions (> 3 vs 3) & $1.93(0.89-4.19)$ & 0.097 \\
\hline BED prescription (> 120 Gy vs < 120 Gy) & $0.25(0.11-0.56)$ & $<0.001$ \\
\hline Tracking (Synchrony vs XSight L./Sp.) & $1.39(0.60-3.24)$ & 0.45 \\
\hline GTV volume (> $10 \mathrm{cc}$ vs < $10 \mathrm{cc}$ ) & $3.46(1.55-7.69)$ & 0.0021 \\
\hline CTV volume ( $>20$ cc vs $<20$ cc) & $2.14(0.97-4.75)$ & 0.063 \\
\hline PTV volume (> 25 cc vs < 25 cc) & $2.00(0.91-4.39)$ & 0.085 \\
\hline GTV mean dose (> 70 Gy vs < 70 Gy) & $0.22(0.079-0.63)$ & 0.0025 \\
\hline CTV mean dose (> 65 Gy vs < 65 Gy) & $0.33(0.15-0.73)$ & 0.0052 \\
\hline PTV mean dose (> 65 Gy vs < 65 Gy) & $0.33(0.15-0.73)$ & 0.0052 \\
\hline GTV D95 (> 60 Gy vs < 60 Gy) & $0.36(0.16-0.79)$ & 0.0096 \\
\hline CTV D95 (> 60 Gy vs < 60 Gy) & $0.40(0.18-0.88)$ & 0.022 \\
\hline PTV D95 (> 60 Gy vs < 60 Gy) & $0.31(0.13-0.76)$ & 0.0077 \\
\hline GTV V160 $0_{\text {BED } 10}(>95 \%$ Vs < $95 \%)$ & $0.39(0.18-0.87)$ & 0.021 \\
\hline CTV V160 ${ }_{\text {BED } 10}(>95 \%$ vs < 95\%) & $0.44(0.20-0.97)$ & 0.041 \\
\hline PTV V160 & $0.47(0.21-1.03)$ & 0.058 \\
\hline GTV D2\% (> 65 Gy vs < 65 Gy) & $0.33(0.15-0.72)$ & 0.0055 \\
\hline GTV D2\% $\%_{\text {BED10 }}$ (> 165 Gy vs < 165 Gy) & $0.32(0.15-0.70)$ & 0.0044 \\
\hline
\end{tabular}

patients grade 2. Regarding late toxicity, RP was slightly worse: two patients developed grade 3 and 1 patient with a centrally located lesion developed grade 4. RP with dyspnea and eventually died due to possible RT-induced pulmonary hemorrhage some 3 month after SBRT treatment. The treatment plan of the patient was analyzed and all treatment parameters and constraints were well below tolerance. The patient had various co-morbidities and was extensively pre-treated with various systemic treatments including bevacizumab.

\section{Discussion}

The management of patients with overt distant metastases from solid tumors is usually considered palliative and are generally treated systemically depending on the primary disease. However, in case of OMLD, metastasisdirected therapy (MDT) has led to excellent long-term survival rates. Indeed, numerous (non-randomized) studies have shown the efficacy and benefit of surgical resections of lung metastases with reported 5-year OS rates up to $68 \%[1,2]$. Randomized trials such as the PulMiCC trial are currently ongoing to evaluate the effect of pulmonary metastasectomy on survival in advanced colorectal cancer [25]. However, in case of surgical or medical inoperability [26], these patients should not be denied MDT. SBRT is a well-documented non-invasive alternative to metastasectomy for a wide range of primary tumors and metastatic locations [8, 20, 27-29]. We present our report of 104 patients with 132 exclusively oligorecurrent lung metastases, all treated consistently with a Cyberknife ${ }^{\bullet}$ system.

Our 1, 2 and 3-year LC rates are in line with reported data on SBRT for lung metastases [30, 31]. In the literature, controversy remains on which characteristics (patient, tumor as well as planning) affect LC. For instance, there is debate on the impact of primary tumor etiology on LC [32-34]. Several studies report a worst LC for lung metastases from primary GI origin while Guckenberger et al. [35] did not observe an influence of different primary tumor histologies on LC. In our series, lung metastases from primary GI origin (34\% of the lesions) showed a superior LC rate compared to primary lung (47\% of the lesions) as well as the other mixed histologies. A possible explanation could be our rather limited number of treated lesions from primary GI etiology and limited variety of histologies of our cohort. The same controversy applies on the impact of metastatic tumor volume on LC $[19,31$, $35,36]$. Our data shows a significant effect (in univariable

Table 5 Multivariable analysis: competing risk regression for LC, Cox regression for lung PFS and OS (distant PFS. Hazard ratio and $p$-value are reported only for the variables included in the multivariable analysis

\begin{tabular}{|c|c|c|c|c|c|c|}
\hline \multirow{2}{*}{$\begin{array}{l}\text { Endpoint } \\
\text { Variables }\end{array}$} & \multirow{2}{*}{$\begin{array}{l}\text { Local control } \\
\text { Hazard ratio (95\% Cl) }\end{array}$} & \multicolumn{2}{|c|}{ Lung PFS } & \multicolumn{3}{|c|}{ Overall survival } \\
\hline & & $p$ value & Hazard ratio $(95 \% \mathrm{Cl})$ & $p$ value & Hazard ratio $(95 \% \mathrm{Cl})$ & $p$ value \\
\hline Primary histology (adeno vs other) & $0.75(0.28-2.02)$ & 0.57 & $0.54(0.28-1.07)$ & 0.078 & $0.57(0.22-1.50)$ & 0.25 \\
\hline \multicolumn{7}{|l|}{ Primary tumor site (reference: Lung) } \\
\hline Gl vs Lung & $0.55(0.14-2.09)$ & 0.38 & $0.90(0.43-1.88)$ & 0.77 & $0.29(0.08-1.02)$ & 0.05 \\
\hline Other vs Lung & $1.00(0.39-2.53)$ & 0.99 & $0.61(0.27-1.38)$ & 0.24 & $0.37(0.11-1.31)$ & 0.12 \\
\hline Prior chemotherapy (yes vs no) & $3.01(0.76-11.92)$ & 0.12 & / & / & / & / \\
\hline Age > 65 (yes vs no) & $0.64(0.24-1.67)$ & 0.36 & / & / & / & / \\
\hline Performance status(1+ vs 0) & $4.00(0.86-18.64)$ & 0.077 & / & / & $2.46(0.56-10.74)$ & 0.23 \\
\hline Gender (male vs female) & $2.17(0.86-5.44)$ & 0.10 & / & / & / & / \\
\hline GTV volume (> 10 cc vs < 10 cc) & $1.92(0.78-4.75)$ & 0.16 & / & / & / & / \\
\hline BED prescription (> 120 Gy vs < 120 Gy) & $0.35(0.14-0.87)$ & 0.025 & / & / & / & / \\
\hline
\end{tabular}


analysis) of metastatic gross tumor volume on LC at the cut-off volume of $10 \mathrm{cc}$. Although other cut-off values have been proposed, our data support the hypothesis that metastatic volume significantly affects LC $[19,36]$. In analogy to SBRT for primary NSCLC, a dose-response relationship has been shown for local tumor control [35]. However, due to a wide variety of treatment techniques, dose fractionation schemes and primary tumors, there remains uncertainty about the optimal dose to irradiate pulmonary metastases. We addressed this particular issue and suggest a biological effective dose (BED10) of 160Gy on the GTV (and CTV) as a critical threshold to significantly improve LC. This dose is at somewhat the higher end of the proposed threshold dose from the literature.

In our cohort, SBRT resulted in a 1, 2 and 3-year overall survival rates of $92.2,80.9$ and $72.0 \%$ respectively. Although to be taken with caution, these OS data compare favourably with other series on SBRT for lung metastases [37] and are at least comparable with those on metastasectomy [38]. A possible explanation for these results might be the high local control rates achieved by SBRT in our serie. In analogy to metastasectomy, patients with a complete resection had a significantly longer OS versus patients where only an incomplete resection was achieved [1]. Moreover, recent randomized trials in the setting of patients with oligometastatic cancers with a controlled primary [39] and patients with OM-NSCLC [40], (consolidative) local therapy was associated with a significant improvement of the OS. These data supports our observations and stresses the importance of local control in obtaining favourable OS in the ORLM setting. Moreover, our OS data tend to confirm previously published results which showed significantly higher OS rates in an ORLM setting when compared to OMLD patients in general [12, 41, 42]. Other relatively favourable clinical characteristics of our patients according to the Niibbe-Onishi-Chang classification [43] could have added to the favourable OS: $77 \%$ of our patients had only 1 metastasis in one site, i.e. lung, mostly from primary NSCLC (47\%) and GI (34\%). In analogy with improved LC, superior OS rates were observed from primary GI site in line with selected literature [44]. Furthermore, patients with a second de-novo metachronous-or repeat ORLM, a new SBRT session was the treatment of choice while in case of polymetastatic progression, patients received next generation systemic therapy and/or targeted agents, which could both add a survival benefit to our cohort. In our study population, out of field lung and distant metastasis were the most important form of treatment failure after SBRT. While a number of patients with repeat ORLM were eligible for subsequent SBRT treatment, the role of adjuvant systemic treatment in this ORLM setting is unclear. Further trials are warranted to evaluate the benefit of adjuvant therapy in this setting.

Our reported low toxicities are in line with previously published data after Cyberknife treatment for primary and metastatic disease [19] and comparable (including the dosimetrical parameters) with treatments performed on a classical linac-based SBRT platform [37, 45].

Limitations of the current investigation include its retrospective nature as well as the variations in treatment schedules, delivered dose, number and limited variations of the primary tumor sites of the treated lesions. Moreover, variability and quantity of previous local and systemic treatments might bias our outcome parameters due to the possible selection of radioresistant cells [46]. No control group was available to compare SBRT with other local treatments such as radiofrequency- and microwave ablation or surgery. Furthermore, only 62 lesions had a confirmed histology. Finally, due to referrals from different institutions, no standardized follow-up imaging protocol was used.

\section{Conclusions}

In conclusion, SBRT as delivered in this study is a highly effective local therapy for the treatment of de-novo metachronous-and repeat oligorecurrent lung metastases and might be able to sterilize a limited number of lesions and achieve long term survival rates in patients with more favourable prognostic features.

\section{Abbreviations \\ SBRT: Stereotactic body radiotherapy; LC : Local control; Di-PFS: Distant progression free survival; OS : Overall survival; OMLD : Oligometastatic lung disease; ORLM: Oligorecurrent lung metastases; CT: Computed tomography; 18F FDG PET: Fluorodeoxyglucose positron emission tomography; GTV: Gross tumor volume; CTV: Clinical target volume; PTV: Planning target volume; OAR: Organs at risk; CR: Complete response; PR: Partial response; SD: Stable disease; BED: Biological effective dose; Cl: Confidence interval; Gy: Gray; MDT: Metastasis-directed therapy; GI: Gastro-intestinal; RP: Radiation pneumonitis; ILD: Interstitial lung disease; IPF: Idiopathic pulmonary fibrosis}

\section{Acknowledgements}

The authors would like to acknowledge Prof. P.A.Coucke, Head of Radiation Oncology department, CHU de Liège, for his organizational support.

\section{Authors' contributions}

PB: guarantor of integrity of the entire study. PB, AG, NJ, LJ: study concepts and design. PB, PVN, LJ, DD: literature research. PB, PVN, LJ: clinical data acquisition. PB, LS, AG: data analysis. GD, AG, LS: statistical analysis. PB, AG, GD, DD: manuscript preparation. PB, ML, GDM, NJ, CM, PL, DD: manuscript editing. All authors read and approved the final manuscript.

\section{Availability of data and materials}

The datasets used and/or analysed during the current study are available from the corresponding author on reasonable request

\section{Ethics approval and consent to participate}

All patients were informed of the intent, possible side effects and practical modalities and provided consent for treatment prior to SBRT as part of a standard of care treatment. No ethics committee approval was required for this retrospective analysis and data access according to national regulations where informed consent is waived in case of retrospective studies (http:// 
www.ejustice.just.fgov.be/eli/wet/2004/05/07/2004022376/justel\#LNK0002). Patients were not treated as part of a study.

\section{Consent for publication}

Not applicable

\section{Competing interests}

The authors declare that they have no competing interests Funding: not applicable.

\section{Author details}

${ }^{1}$ Department of Radiation Oncology, University Hospitals Leuven, Herestraat 49, 3000 Leuven, Belgium. '2Department of Radiation Oncology, University Hospital of Liège, Avenue de L'Hòpital 1, 4000 Liège, Belgium. ${ }^{3}$ Medical Physics Department, Jules Bordet Institute, Université Libre de Bruxelles, 1 rue Héger-Bordet, 1000 Brussels, Belgium.

\section{Received: 31 August 2019 Accepted: 27 April 2020 Published online: 08 May 2020}

\section{References}

1. Pastorino U, Buyse M, Friedel G, Ginsberg RJ, Girard P, Goldstraw P, et al. Long-term results of lung metastasectomy: prognostic analyses based on 5206 cases. J Thorac Cardiovasc Surg. 1997;113(1):37-49.

2. Treasure T, Milosevic M, Fiorentino F, Macbeth F. Pulmonary metastasectomy: what is the practice and where is the evidence for effectiveness? Thorax. 2014:1-4.

3. Van Raemdonck D, Friedel G. The European Society of Thoracic Surgeons lung Metastasectomy project. J Thorac Oncol. 2010;5(6):127-9.

4. Weichselbaum RR, Hellman S. Oligometastases revisited. Nat Rev Clin Oncol. 2011;8(6):378-82.

5. Boyer MJ, Ricardi U, Ball D, Salama JK. Ablative approaches for pulmonary metastases. Thorac Surg Clin. 2016;26(1):19-34

6. Corbin KS, Hellman S, Weichselbaum RR. Extracranial oligometastases: a subset of metastases curable with stereotactic radiotherapy. J Clin Oncol. 2013;31(11):1384-90.

7. Salama JK, Milano MT. Radical irradiation of extracranial oligometastases. J Clin Oncol. 2014;32(26):2902-12.

8. Tree AC, Khoo VS, Eeles RA, Ahmed M, Dearnaley DP, Hawkins MA, et al. Stereotactic body radiotherapy for oligometastases. Lancet Oncol. 2013; 14(1):e28-37.

9. Shultz DB, Filippi AR, Thariat J, Mornex F, Loo BW, Ricardi U. Stereotactic ablative radiotherapy for pulmonary oligometastases and oligometastatic lung cancer. J Thorac Oncol. 2014;9(10):1426-33.

10. Lancia A, Ingrosso G, Carosi A, Di Murro L, Giudice E, Cicchetti S, et al. Oligometastatic cancer: stereotactic ablative radiotherapy for patients affected by isolated body metastasis. Acta Oncol (Madr). 2017;56(11):1621-5.

11. Niibe $Y$, Hayakawa K. Oligometastases and oligo-recurrence: the new era of cancer therapy. Jpn J Clin Oncol. 2010;40(2):107-11.

12. Yamashita H, Niibe $Y$, Yamamoto T, Katsui K, Jingu K, Kanazawa S, et al. Lung stereotactic radiotherapy for oligometastases: comparison of oligorecurrence and sync-oligometastases. Jpn J Clin Oncol. 2016;46(7):687-91.

13. Inoue $\mathrm{T}$, Katoh $\mathrm{N}$, Onimaru $\mathrm{R}$, Shirato $\mathrm{H}$. Clinical outcomes of stereotactic body radiotherapy for patients with lung tumors in the state of Oligorecurrence. Pulm Med. 2012;2012:1-5.

14. Sloth Møller D, Knap MM, Nyeng TB, Khalil AA, Holt MI, Kandi M, et al. Difference in target definition using three different methods to include respiratory motion in radiotherapy of lung cancer. Acta Oncol. 2017;56(11): 1604-9.

15. Boda-Heggemann J, Frauenfeld A, Weiss C, Simeonova A, Neumaier C, Siebenlist $\mathrm{K}$, et al. Clinical outcome of hypofractionated breath-hold imageguided SABR of primary lung tumors and lung metastases. Radiat Oncol. 2014:9:10.

16. Nuyttens JJ, Van De Pol M. The CyberKnife radiosurgery system for lung cancer. Expert Rev Med Devices. 2012;9(5):465-75.

17. Guckenberger M, Lievens Y, Bouma AB, Collette L, Dekker A, deSouza NM, et al. Characterisation and classification of oligometastatic disease: a European Society for Radiotherapy and Oncology and European Organisation for Research and Treatment of Cancer consensus recommendation. Vol. 21, The Lancet Oncology. Lancet Publishing Group. 2020:e18-28.
18. Kuduvalli G. Multiple Fiducial identification using the hidden Markov model in image guided radiosurgery. Conf Comput Vis Pattern Recognit Work. 2006;2006:92

19. Janvary ZL, Jansen N, Baart V, Devillers M, Dechambre $D$, Lenaerts $E$, et al. Clinical outcomes of 130 patients with primary and secondary lung tumors treated with Cyberknife robotic stereotactic body radiotherapy. Radiol Oncol. 2017;51(2):178-86.

20. Berkovic P, Gulyban A, Nguyen PV, Dechambre D, Martinive P, Jansen N, et al. Stereotactic Robotic Body Radiotherapy for Patients With Unresectable Hepatic Oligorecurrence. Clin Colorectal Cancer. 2017;16(4).

21. Timmerman RD. An overview of Hypofractionation and introduction to this issue of seminars in radiation oncology. Semin Radiat Oncol. 2008;18(4):215-22.

22. Dechambre $D$, Janvary $L Z$, Jansen N, Berkovic P, Mievis C, Baart V, et al. Prediction of GTV median dose differences eases Monte Carlo represcription in lung SBRT. Phys Medica. 2018:45.

23. Eisenhauer EA, Therasse P, Bogaerts J, Schwartz LH, Sargent D, Ford R, et al. New response evaluation criteria in solid tumours: revised RECIST guideline (version 1.1). Eur J Cancer. 2009;45(2):228-47.

24. Dept of Health and Human Services U. Common terminology criteria for adverse events (CTCAE) version 4.0. National Institutes of Health. 2009.

25. Treasure T, Fallowfield L, Lees B. Pulmonary metastasectomy in colorectal cancer: the PuIMiCC trial. J Thorac Oncol. 2010;5(6 Suppl 2):S203-6.

26. Detterbeck FC, Lewis SZ, Diekemper R, Addrizzo-Harris D, Alberts WM. Executive summary: diagnosis and management of lung cancer, $3 \mathrm{rd}$ ed: American College of Chest Physicians evidence-based clinical practice guidelines. Chest. 2013;143(5 Suppl):7S-37S.

27. Høyer M, Swaminath A, Bydder S, Lock M, Méndez Romero A, Kavanagh B, et al. Radiotherapy for liver metastases: a review of evidence. Int J Radiat Oncol Biol Phys. 2012;82(3):1047-57.

28. Berkovic P, De Meerleer G, Delrue L, Lambert B, Fonteyne V, Lumen N, et al. Salvage stereotactic body radiotherapy for patients with limited prostate cancer metastases: Deferring androgen deprivation therapy. Clin Genitourin Cancer. 2013;11(1)

29. Park JJ, Hajj C, Reyngold M, Shi W, Zhang Z, Cuaron JJ, et al. Stereotactic body radiation vs. intensity-modulated radiation for unresectable pancreatic cancer. Acta Oncol. 2017;56(12):1746-53.

30. Rieber J, Streblow J, Uhlmann L, Flentje M, Duma M, Ernst I, et al. Stereotactic body radiotherapy (SBRT) for medically inoperable lung metastases-A pooled analysis of the German working group "stereotactic radiotherapy.". Lung Cancer. 2016;97:51-8.

31. Sharma A, Duijm M, Oomen-de Hoop E, Aerts JG, Verhoef C, Hoogeman M, et al. Factors affecting local control of pulmonary oligometastases treated with stereotactic body radiotherapy. Acta Oncol (Madr). 2018;28:1-7.

32. Helou J, Thibault I, Poon I, Chiang A, Jain S, Soliman H, et al. Stereotactic ablative radiation therapy for pulmonary metastases: histology, dose, and indication matter. Int J Radiat Oncol. 2017;98(2):419-27.

33. Binkley MS, Trakul N, Jacobs LR, Von Eyben R, Le QT, Maxim PG, et al. Colorectal histology is associated with an increased risk of local failure in lung metastases treated with stereotactic ablative radiation therapy. Int J Radiat Oncol Biol Phys. 2015;92(5):1044-52.

34. Agolli L, Bracci S, Nicosia L, Valeriani M, De Sanctis V, Osti MF. Lung metastases treated with stereotactic ablative radiation therapy in Oligometastatic colorectal Cancer patients: outcomes and prognostic factors after long-term follow-up. Clin Colorectal Cancer. 2017;16(1): 58-64.

35. Guckenberger M, Klement RJ, Allgäuer M, Andratschke N, Blanck O, BodaHeggemann J, et al. Local tumor control probability modeling of primary and secondary lung tumors in stereotactic body radiotherapy. Radiother Oncol. 2016;118:485-91.

36. Yamamoto $T$, Jingu $K$, Shirata $Y$, Koto $M$, Matsushita $H$, Sugawara $T$, et al Outcomes after stereotactic body radiotherapy for lung tumors, with emphasis on comparison of primary lung cancer and metastatic lung tumors. BMC Cancer. 2014;14:464

37. Siva S, Slotman BJ. Stereotactic ablative body radiotherapy for lung metastases: where is the evidence and what are we doing with it? Semin Radiat Oncol. 2017;27(3):229-39.

38. Widder J, Klinkenberg TJ, Ubbels JF, Wiegman EM, Groen HJM, Langendijk JA. Pulmonary oligometastases: Metastasectomy or stereotactic ablative radiotherapy? Radiother Oncol. 2013;107(3):409-13.

39. Palma DA, Olson R, Harrow S, Gaede S, Louie A V, Haasbeek C, et al. Stereotactic ablative radiotherapy versus standard of care palliative 
treatment in patients with oligometastatic cancers (SABR-COMET): a randomised, phase 2, open-label trial. www.thelancet.com. 2019;393.

40. Gomez DR, Tang C, Zhang J, Blumenschein GR, Hernandez M, Jack Lee J, et al. Local consolidative therapy vs. maintenance therapy or observation for patients with oligometastatic non-small-cell lung cancer: long-term results of a multi-institutional, phase II, randomized study. J Clin Oncol. 2019;37(18):1558-65.

41. Niibe Y, Yamashita H, Sekiguchi K, Takahashi W, Shiraishi K, Okuma K, et al. Stereotactic body radiotherapy results for pulmonary Oligometastases: a twoinstitution collaborative investigation. Anticancer Res. 2015;35(9):4903-8.

42. Aoki M, Hatayama Y, Kawaguchi H, Hirose K, Sato M, Akimoto H, et al. Stereotactic body radiotherapy for lung metastases as oligo-recurrence: a single institutional study. J Radiat Res. 2016;57(1):55-61.

43. Niibe Y, Chang JY, Onishi H, Salama J, Hiraki T, Yamashita H. Editorial Oligometastases/Oligo-Recurrence of Lung Cancer; 2013. p. 438236.

44. Sharma A, Duijm M, Oomen-de Hoop E, Aerts JG, Verhoef C, Hoogeman M, et al. Survival and prognostic factors of pulmonary oligometastases treated with stereotactic body radiotherapy. Acta Oncol (Madr). 2019;58(1):74-80.

45. Tekatli H, Tetar SU, Nguyen TK, Warner A, Verbakel WF, Palma DA, et al. Optimizing SABR delivery for synchronous multiple lung tumors using volumetric-modulated arc therapy. Acta Oncol. 2017;56(4):548-54.

46. Willers H, Azzoli CG, Santivasi WL, Xia F. Basic mechanisms of therapeutic resistance to radiation and chemotherapy in lung cancer. Cancer J. 2013; 19(3):200-7.

\section{Publisher's Note}

Springer Nature remains neutral with regard to jurisdictional claims in published maps and institutional affiliations.

Ready to submit your research? Choose BMC and benefit from:

- fast, convenient online submission

- thorough peer review by experienced researchers in your field

- rapid publication on acceptance

- support for research data, including large and complex data types

- gold Open Access which fosters wider collaboration and increased citations

- maximum visibility for your research: over $100 \mathrm{M}$ website views per year

At $\mathrm{BMC}$, research is always in progress.

Learn more biomedcentral.com/submissions 